ISSN 1981-416X

\title{
Contribuições dos Quefazeres de Paulo Freire para a educação do campo hoje
}

\author{
Contributions of Paulo Freire's human activity \\ for the nowadays field education
}

\section{Contribuciones de los quehaceres de Paulo Freire para la educación del campo hoy}

\section{Sheila de Fatima Mangoli Rocha ${ }^{[a]}$, Gomercindo Ghiggi ${ }^{[b]}$, Priscila Monteiro Chaves ${ }^{[c]}$, Dirlei de Azambuja Pereira ${ }^{[d]}{ }^{*}$}

\author{
[a] Universidade Federal de Roraima (UFRR), Boa Vista, RR, Brasil \\ [b] Universidade Federal de Pelotas (UFPEL), Pelotas, RS, Brasil \\ [c] Universidade do Oeste de Santa Catarina (UNOESC), Joaçaba, SC, Brasil \\ [d] Universidade Federal de Pelotas (UFPel), Pelotas, SC, Brasil
}

\section{Resumo}

É necessário buscar contribuições teórico-metodológicas para a prática docente em Freire para a concretização da educação popular do campo. A presente pesquisa teórico-bibliográfica objetiva problematizar os quefazeres da teoria freiriana frente às práticas pedagógicas, no que compete à busca por uma educação que possa contribuir com a construção de uma sociedade justa e igualitária, na medida em que atenda às necessidades

*SFMR: Doutora em Educação, e-mail: sheilamangoli@gmail.com GG: Doutor em Educação, e-mail: ghiggi@terra.com.br

PMC: Doutora em Educação, e-mail: priscila.chaves@unoesc.edu.br

DAP: Doutor em Educação, e-mail: pereiradirle@gmail.com 
das classes populares, tendo a realidade do campo como ponto de partida. Para tanto, três categorias de análise foram elegidas, são elas: formação humana, tema gerador e a conjugação entre saberes científicos e populares. Embora esse educador seja considerado um dos principais referenciais, ainda existe carência de estudos sistemáticos de suas contribuições em categorias que visem a favorecer o preenchimento de lacunas nas práticas educativas de desenvolvimento do campo. Por fim, faz-se necessário avigorar que a educação não seja meio de fuga do campo, mas de obtenção de melhoria das condições de vida; reivindicação de um projeto de formação aliado a um modelo de agricultura que não mate a dignidade do homem.

Palavras-chave: Quefazeres. Educação do Campo. Paulo Freire.

\begin{abstract}
It is necessary to seek theoretical-methodological contributions to the teaching practice in Freire for the realization of the popular field education. The present theoretical-bibliographical research aims to problematize the aspects of Freire's theory of human activity to pedagogical practices, in what concerns the search for an education that can contribute to the construction of a fair and egalitarian society, insofar as it meets the needs of the popular classes, having the reality of the field as a starting point. In order to do so, three categories of analysis were chosen: human formation, generative theme and the combination of scientific and popular knowledge. Although this educator is considered one of the main references, there is still a lack of systematic studies of his contributions in categories which aim to favor the filling of gaps in the educational practices of field development. Finally, it is necessary to invigorate that education is not a mean of escape from the field, but of obtaining an improvement in living conditions; claiming a training project allied to a model of agriculture that does not kill the dignity of men.
\end{abstract}

Keywords: Human activity. Field Education. Paulo Freire. 


\section{Resumen}

Es necesario buscar contribuciones teórico-metodológicas para la práctica docente en Freire para la concreción de la educación popular del campo. La presente investigación teórico-bibliográfica objetiva problematizar los quehaceres de la teoría freiriana a las prácticas pedagógicas, en lo que compete a la búsqueda de una educación que pueda contribuir con la construcción de una sociedad justa e igualitaria, en la medida en que atienda a las necesidades de las clases populares, teniendo la realidad del campo como punto de partida. Para ello, tres categorías de análisis fueron elegidas, son ellas: formación humana, tema generador y la conjugación entre saberes cientificos y populares. Aunque este educador es considerado uno de los principales referenciales, todavía existe carencia de estudios sistemáticos de sus contribuciones en categorías que apunten a favorecer el llenado de lagunas en las prácticas educativas de desarrollo del campo. Por último, se hace necesario afrontar que la educación no sea un medio de fuga del campo, sino de obtención de mejora de las condiciones de vida; la reivindicación de un proyecto de formación aliado a un modelo de agricultura que no mate la dignidad del hombre.

Palabras clave: Quehaceres. Educación del Campo. Paulo Freire.

\section{Introdução}

A presente discussão tem em seu âmago o reconhecimento de que as ideias trazidas criticamente a descoberto no âmbito das questões relativas à educação, enquanto formação humana, se desenvolvem em uma sociedade de classes e a transformação radical da sociedade, central na biobibliografia de Freire, interessa à classe trabalhadora, de forma geral, e aos trabalhadores rurais, em especial. Nesse sentido, nos últimos anos, vem crescendo um movimento chamado Educação do Campo ${ }^{1}$,

1 Esta é uma área relativamente nova. Há não muito tempo o modelo vigente era de "Educação Rural", como uma forma de extensão da educação urbana, sem contemplar as especificidades e 
fruto da luta dos trabalhadores rurais pela consolidação de uma educação pensada e realizada a partir de seus interesses.

As discussões relativas à Educação do Campo surgem relacionadas aos aspectos econômicos (expansão do modelo capitalista de agricultura), sociais (aumento da pobreza e exclusão social no campo) e educacionais (ausência de propostas e políticas educacionais voltadas à população que vive no e do campo). Logo de saída, resta claro que as propostas de Educação do Campo vinculam um projeto de educação a um projeto de sociedade. Desse modo, a educação está articulada a um modelo de desenvolvimento sustentável, baseado no respeito à dignidade humana. "A materialidade de origem da Educação do Campo projeta/constrói uma determinada totalidade de relação que lhes são constitutivas. Antes (ou junto) de uma concepção de educação", ela é uma concepção de sociedade e de política, no sentido mais original do termo, no que se refere à organização social das pessoas. Isto é, "como pensamos o campo pensamos a educação; se pensarmos o campo como um latifúndio não temos como pensar a Educação do Campo; se pensarmos a Reforma Agrária como uma política compensatória apenas, não vamos pensar em um sistema público de educação para os camponeses" (CALDART, 2004, p. 15).

E, nesse fito, as concepções teóricas, bem como a prática de Freire como educador, auxiliam a construção de propostas educacionais do campo, em contraposição às propostas para o campo. Pensando com Freire, é possível compreender que, a partir das tensões próprias dos movimentos humanos dentro das organizações sociais, podem ser criadas condições para que as pessoas possam dizer a palavra. Vale ressaltar que, no pensamento freiriano, dizer a palavra é condição para que o ser humano preencha-se de significação enquanto tal.

Com esse entendimento, torna-se viável - e inevitável — buscar contribuições teórico-metodológicas à prática docente em Freire para a concretização da educação popular do campo. Educação não limitada

necessidades da população do campo. Somente em 1998 a Educação do Campo foi proposta em nível nacional durante a 1aㅡ Conferência por uma Educação Básica do Campo. 
ao processo instrucional, mas constitutiva do processo formativo do ser humano, consciente de sua historicidade. Tanto mais importante se torna esse entendimento quanto mais o avanço do capital ocorre, através de seus grandes empreendimentos, que ferem o modo de vida da população do campo e ameaçam sua existência. Nesse cenário, os projetos de formação humana, atrelados à Educação do Campo, configuram defesa do campo e visam à consolidação de vida digna às pessoas que vivem no e do campo.

Fazendo eco aos movimentos sociais, e traçando um estado da questão, é possível encontrar pesquisas que antecedem esta, em que diversos autores defendem e reconhecem que os povos do campo têm um modo de vida e de produzir a existência, diferenciados. Eles fazem parte de uma cultura diferente da urbana, produzindo relações sociais e de trabalho distintas, o que demanda e justifica uma organização educativa singular. E, na avaliação de Antônio e Lucini (2007), as asserções de Freire, na medida em que respondem às necessidades das classes trabalhadoras, possibilitam-lhes reconhecerem-se em suas propostas educativas, permitindo ser apropriada e reinventada pelos educadores populares do campo.

Autores outros já avançaram a discussão acerca da necessidade de ultrapassar os limites de um modelo tradicional de educação, de "herança colonial e urbanocêntrica, alienante e submissa aos interesses do grande capital e do latifúndio" (NOSELLA, 2012, p. 256) - porque esse modelo não contempla a população do campo em sua realidade e seus saberes (CALDART, 2003). O mesmo ocorre no que concerne à potência do pensamento de Freire para referendar práticas pedagógicas libertadoras. Em suas pesquisas, Saul e Silva (2014) manifestaram que o pensamento de Freire deve ser tomado como um crivo de denúncia e anúncio de concepções e práticas curriculares. Manifestação essa encerrada em uma proposta contra-hegemônica, baseada na construção de práticas emancipatórias. Pelizzari et al. (2008) demonstraram o forçoso progresso que carecem as formas de avaliação, problematizando a necessidade de repensar os referenciais teóricos para avançar na prática da escola que não é urbanizada, o que acarreta maior preocupação com a formação dos professores/educadores. 
Freire é reconhecido como o grande referencial brasileiro para a educação do campo, com contribuições diversas. Conforme afirmação de Caldart (2003), a educação do campo talvez possa ser considerada uma das realizações práticas da Pedagogia do Oprimido, à medida que afirma os pobres do campo como sujeitos legítimos de um projeto educativo emancipatório. É importante aclarar que, embora Freire esteja difuso, em diversas ideias em defesa da Educação do Campo, buscar destacar categorias para análise sistemática torna mais fecundo o seu referencial na concretização do modelo de educação e desenvolvimento do campo.

Partindo deste mapeamento (e sem pretensão de apresentar minuciosamente todos os aspectos que podem ser problematizados), por meio de uma pesquisa teórico-bibliográfica (GIL, 2002; LUNA, 1999) e de cunho filosófico (SEVERINO, 2002), são problematizadas contribuições dos quefazeres da teoria freiriana às práticas pedagógicas, essenciais a uma educação que possa contribuir com a construção de uma sociedade justa e igualitária, na medida em que atenda às necessidades das classes populares, tendo a realidade do campo como ponto de partida. Para tanto, três categorias de análise foram elegidas, são elas: formação humana, tema gerador e a conjugação entre saberes científicos e populares.

\section{Preceitos e arestas para pensar a educação a partir de Freire}

Antes de entrar mais designadamente na discussão central, cabe tecer algumas considerações referentes às não raras leituras apressadas de Freire, que levam, em última instância, a práticas dissonantes das suas propostas. Uma leitura precária de Freire produz certo encantamento, percebido na reprodução de suas frases, que, embora possam soar bem aos ouvidos, são por vezes rasas e exauridas de sentido político quando descoladas do conjunto de sua obra, bem como de suas principais influências epistemológicas.

Por um lado, é preciso ter clareza de que as práticas pedagógicas orientadas pela concepção freiriana de educação não podem ser 
dissociadas de uma opção política em favor dos oprimidos, em favor da transformação social radical, baseando-se na "[...] certeza de que mudar é difícil, mas é possível. É o que nos faz recusar qualquer posição fatalista que empresta a este ou àquele fator condicionante um poder determinante, diante do qual nada se pode fazer" (FREIRE, 2000, p. 26). Assim, o convite de Freire em prol da compreensão de sua perspectiva começa pela afirmação de que o ser humano é condicionado, mas não determinado, de forma que mudar é tanto difícil, quanto possível. Por outro, o pensamento de Freire, amplamente conhecido e reconhecido, enfoca um aspecto inexpugnável da educação do campo: o protagonismo da população do campo no processo educativo como condição da sua construção. Todos - docentes, discentes e comunidade - precisam estar envolvidos e articulados para pôr em andamento uma educação pensada em seus aspectos sociais, políticos e culturais, encarando sua própria realidade, não como dada, mas como elemento em constante construção e reconstrução.

Permeia a educação do campo, tal qual a perspectiva de Freire, uma intenção maior que a discussão da educação, mas da qual essa faz parte. Ou seja, o movimento indispensável de luta por um projeto popular de desenvolvimento, que contemple, evidentemente, uma educação verdadeiramente do campo. Ao propor uma educação dialógica visando à emancipação das pessoas, Freire aponta a necessidade de as contradições básicas das situações concretas vividas por educadores e educandos estarem no centro do currículo. Na educação do campo significa trazer ao debate as concepções de campo e de desenvolvimento, constituídas pelas lutas e desafios dos diversos povos que vivem no meio rural. Dessa forma, a educação do campo se constitui em diálogo com as questões gerais da educação, mirando a concepção de ser humano e de formação humana. O diferencial consiste, justamente, na definição irrevogável de princípios educativos que respeitem a constituição dos povos do campo, entendidos não somente como participantes, mas como sujeitos do processo.

Nesse sentido, pelo diálogo se constitui o legado freiriano de impacto em todas as instâncias da educação. O diálogo, conforme afirmado repetidamente por Freire, implica transformação. Ele não se resume à 
comunicação, possui duas dimensões, a saber, a ação e a reflexão (práxis), e se constitui em relação horizontal, encontro entre homens e mulheres mediatizados pelo mundo. A importância do diálogo em seu pensamento está expressa na magnitude de sua afirmação "[...] dizendo a palavra com que, pronunciando o mundo, os homens o transformam, o diálogo se impõe como caminho pelo qual os homens ganham significação enquanto homens" (FREIRE, 2016, p. 135). Essa compreensão tem repercussão nas práticas pedagógicas, nas formas de relacionamento estabelecidas nos processos educativos, pois, conforme asseverado por Freire (2016, p. 134): "Existir, humanamente, é pronunciar o mundo, é modificá-lo. O mundo pronunciado, por sua vez, se volta problematizado aos sujeitos pronunciantes, a exigir deles novo pronunciar".

Freire assevera que, com dignidade, é necessário dialogar com o doutor, o delegado, o juiz. Pinto (2006), ao defender uma proposta de Escola Itinerante, atualiza a proposição de Freire quanto à necessidade de dizer sua própria palavra e, ainda assim, escrever nas normas da língua padrão. Isso nos coloca o imperativo de não perder de vista que a cultura camponesa não pode ser tudo o que os alunos do campo precisam estudar, e sim precisa estar associada ao modelo de produção da existência e ao conjunto do processo de ensino-aprendizagem de que irão participar, "pois no ambiente que convivem e passarão a conviver no futuro deve haver essa relação de reconhecimento do que elas já sabem e o que irão aprender no processo real da sala de aula e em seu convívio social" (PINTO, 2006, p. 51).

Talvez ainda seja relevante acrescentar que o modelo de desenvolvimento articulado à Educação do Campo não é particular e não está restrito aos povos do campo ${ }^{2}$. Não é uma luta da população do campo, mas de toda a sociedade. Pois, como definido por Fernandes (2002), rural e urbano são espaços geográficos singulares e plurais, autônomos e

2 Há grande diversidade na designação geral de "povos do campo" que inclui ribeirinhos, pescadores artesanais, quilombolas, acampados e assentados da reforma agrária, agricultores familiares, extrativistas, caiçaras, povos da floresta, caboclos, trabalhadores rurais assalariados, indígenas e enfim, por intermédio do Decreto $\mathrm{n}$ - 7.352/2010, todos aqueles que produzam suas condições materiais de existência a partir do trabalho no meio rural. 
interativos, com suas identidades culturais e modos de organização diferenciados. Por isso, não faz sentido a crença em uma relação de dependência eterna, bem como na intensificação da urbanização como modelo de país moderno. Certamente, o desenvolvimento brasileiro deve passar pelo desenvolvimento humano de todo o povo.

Sem perder de vista tais preceitos é que as três categorias de análise foram estruturadas no presente estudo, buscando colaborar com a compreensão de um outro tipo de escola, que, ao mesmo tempo, não descaracteriza os interesses e prioridades do homem do campo e possibilita uma ação cultural que transcende a mera reprodução e excitação de palavras de ordem. As categorias aqui estruturadas partem da necessidade que o ser humano tem de aprender a compreender o que está escrito, calcular, ter contato com o conhecimento científico, ao mesmo tempo que busca ler, refletir e modificar as condições materiais circunscritas.

\section{Formação humana}

O conceito de conhecimento proposto por Freire é um sinalizador imprescindível às práticas pedagógicas comprometidas com a formação humana. Como já é sabido, segundo Freire, conhecer, na dimensão humana, não é o ato através do qual um sujeito, transformado em objeto, recebe, dócil e passivamente, os conteúdos que outro lhe dá ou impõe. O conhecimento, pelo contrário, exige uma presença curiosa do sujeito em face do mundo, requer sua ação transformadora sobre a realidade, demanda uma busca constante e implica em invenção e em reinvenção.

Segundo Saul e Silva (2014), a compreensão de Freire sobre o ato de conhecer é essencial para a análise dos contextos escolares e, de maneira especial, para o campo. Pois, não raramente, o currículo centrado em disciplinas, apresenta os conhecimentos descontextualizados, como se fossem neutros, não possibilitando a identificação das tensões que o geraram. "O conhecimento é então veiculado na prática pedagógica sem que se diferenciem suas dimensões e critérios epistemológicos gestados 
em disputas socioculturais, seus processos históricos e contextos de produção, seus limites de validade" (SAUL; SILVA, 2014, p. 2068-2069).

Freire, por outro lado, propõe a valorização dos diferentes tipos de conhecimento. A valorização dos saberes dos educandos, seus saberes de experiência feitos, permite o reconhecimento das diferenças de produção e a apropriação dos diversos tipos de conhecimento, bem como a ampliação e diversificação daqueles precedentes, uma vez que, conforme defendido por Saviani (1996), as práticas pedagógicas devem ter como ponto de partida e de chegada as práticas sociais. Miguel Arroyo (2000, p. 68) atualiza essa proposta freiriana preconizando que "a educação abrange os processos formativos que se desenvolvem na vida familiar, na convivência humana, no trabalho, nas instituições de ensino e pesquisa, nos movimentos sociais e organizações da sociedade civil e nas manifestações culturais". Entretanto, em modelos de currículo em que o conhecimento é revestido por certa cientificidade, completamente isento de valores e a-histórico, não há lugar para um conhecimento contextualizado e construído na relação com a realidade concreta. Conforme denunciado por Saul e Silva (2014, p. 2069),

[...] o conhecimento, desumanizado em nome de uma objetividade inexistente, distanciado de realidades e de práticas sociais, desqualificado de significados - torna-se inútil como elemento de intervenção e de uso social. Nessa perspectiva axiológica, não se reconhecem os diferentes padrões de validade para conhecimentos e práticas, os respectivos limites históricos das verdades em seus contextos.

Teoria e prática são indissociáveis, de forma que as concepções se materializam nas práticas pedagógicas, exigindo coerência. Portanto, o que se pretende colocar em relevo é a existência de elementos, em Freire, capazes de contribuir para a consolidação de práticas pedagógicas baseadas na possibilidade de construção de uma realidade justa e solidária.

É notório que a mais significativa influência de Freire quanto à referida relação advém da proposta marxiana de práxis, que, observada na contemporaneidade, refere-se também à necessidade de avançar na 
sistematização de experiências de solidariedade que as pessoas são capazes de praticar. Se a vida se reduz à competição, à luta, à destruição dos mais fracos pelos mais fortes e se o motor da história é tão-só a luta de classes, que por vezes acaba seguindo frágeis leituras marxistas, onde fica o mistério da gratuidade, da humanidade e do amor mundi (ARENDT, 1997)? Tais valores de solidariedade - presença forte no campo e entre os mais pobres - praticados por Freire e reclamados à organização social, existentes nos movimentos sociais e organizações populares, não têm sido preocupação da metafísica ou de filósofos, santos ou profetas. Por vezes, cientistas, pesquisando a evolução, contestam o darwinismo biológico e social, mostram a dimensão da vida gerada por complexas simbioses, mas as relações entre preocupações de formação da singularidade do sujeito e atuação na coletividade, por meio da práxis, não têm sido prioridade na briga paradigmática constante entre críticos e pós-estruturalistas.

De modo que existir humanamente extrapola os perímetros desses paradigmas, que são importantes porque ajudam a pensar o mundo, mas que, em uma visão estreitada ao extremo, acaba desconsiderando outros aspectos da formação dos seres humanos, como a constituição de valores sociais e éticos que são importantes, em especial, na Educação do Campo, onde a comunidade é co-responsável pela formação do jovem. Responsabilidade manifesta, por exemplo, nos modelos de escola-família agrícola, em regime de alternância, no tempo-comunidade, os cuidados com o educar rompem com os limites dos interesses individuais.

Com cautela, Leandro Konder, em O futuro da filosofia da práxis (1992, p. 128), vivifica esse conceito alertando que "[...] a práxis, na concepção de Marx, não se limitou a unir a theoria e a poiésis (atividade de produção material), pois envolvia, necessariamente, a atividade política do cidadão, sua participação nos debates e nas deliberações da comunidade, suas atitudes na relação com os outros cidadãos, a ação moral, intersubjetiva". O processo de formação humana deve abranger a inserção ativa das novas gerações em sua cultura, e isto não equivale à formação unilateral, caracterizada, preponderantemente, pela formação científica, voltada ao desenvolvimento de competências e à aquisição de habilidades para a entrada no 
mercado de trabalho, que é o comum na sociedade capitalista, bem como não se resume à razão instrumental. Em Freire (2001, p. 19) se destaca a ideia de que "[...] para ser válida, toda educação, toda ação educativa deve necessariamente estar precedida de uma reflexão sobre o homem e de uma análise do meio de vida concreto do homem concreto a quem queremos educar (ou melhor dito: a quem queremos ajudar a educar-se)".

Nesse sentido, Freire propõe que a educação, ao longo da história da civilização ocidental, identifique-se como processo de formação humana. Essa formação significa a própria humanização do homem, concebido como inacabado, porém dotado da capacidade de transformar-se. Quando se fala em educação entendida como processo de formação humana, para além de qualquer processo de qualificação técnica, relacionado a uma lateralidade, o que está em pauta é uma situação de conquista de plena humanidade. Por isso, a razão formal, se tomada exclusivamente, não consegue atingir a meta de formação de um ser humano completo.

É importante mencionar também, ainda que de modo amplo, algumas das contribuições de Paulo Freire para o tema que nos ocupa que inauguram uma nova perspectiva, pelo método dialógico que propõe implementar nos processos educativos, uma vez que se pode considerar que seu pensamento já adiantava aspectos importantes do que hoje se configura como a perspectiva intercultural na educação. Segundo Gohn (2002, p. 67), "nos anos 90, Freire destaca ainda mais a dimensão cultural nos processos de transformação social e o papel da cultura no ato educacional”. Além de reforçar seus argumentos em defesa de uma educação libertadora que respeite a cultura e a experiência anterior dos educandos, Freire alerta para as múltiplas dimensões da cultura, principalmente a cultura midiática. Ele chama atenção para o fato de que ela poderá despertar-nos para alguns temas geradores que o próprio saber escolar ignora, ou valoriza pouco, como a pobreza, a violência, etc. Destaca também que a mídia trabalha e explora a sensibilidade das pessoas e por isso consegue atrair e monopolizar as atenções. Seus livros escritos nos anos 90 - de estilo mais literário - revelam um pensador preocupado com o futuro da sociedade em que vivemos, dado o crescimento da violência, da intolerância e das desigualdades 
socioeconômicas. Ele destacará a importância da ética e de uma cultura da diversidade. Por isso, a educação do campo está vinculada às causas, aos desafios, aos sonhos, à história e à cultura dos povos do campo. E, se as contribuições de Freire são amplas para a prática em geral, devido sua fecunda concepção educacional, o tema gerador talvez seja a contribuição mais efetiva, do ponto de vista estritamente metodológico, também para a educação do campo, como será analisado na seguinte seção.

\section{Tema gerador e Educação do Campo}

Em se tratando da educação do campo, esta categoria se mostra tanto frutífera quanto mais considerarmos o uso da fusão entre preposição de e artigo $o$, distinção essa que já fora apresentada por Freire ao explicar a escolha do título Pedagogia do ${ }^{3}$ Oprimido. Segundo Pingas (2006, p. 41), quando as ações são "pensadas 'para' o campo são co-intencionadas para atender ao modelo de desenvolvimento determinado pelas elites e o mercado". Daí a necessidade de uma educação do campo, que não seja projetada meramente por "especialistas, mas uma educação dos povos sujeitos do campo; uma educação carregada de vida, associada aos sentimentos, à simbologia, ao jeito de viver, à luta, à resistência, ao sonho, enfim, associada a uma vida digna impossível de acontecer numa sociedade com viés capitalista”.

Nesse sentido, o tema gerador é do campo, e não para o campo e, por isso, sua escolha não está centrada no educador, o que não o isenta de sua responsabilidade de organizá-lo pedagogicamente, definir questões norteadoras, planejar conteúdos e práticas adequadas. Porém, a organização da prática por meio do tema gerador fortalece a relação entre

3 Freire chama a atenção do leitor à dicotomia para/do, não sugerindo uma pedagogia para o oprimido, visto que a competência se encontra nas mãos do mesmo, (e por isso do) somente ele tem a poder de restaurar sua humanidade. E argumenta: "Por isto é que somente os oprimidos, libertando-se, podem libertar os opressores. Estes, enquanto classe que oprime, nem libertam, nem se libertam" (FREIRE, 2016, p. 82). 
educando, educador e comunidade, os quais se unem para discutir os problemas da sua realidade. Essa proposta remete aos primórdios da atuação de Freire, em Angicos, ainda na década de 1960, com sua reconhecida experiência educativa. Todavia, essa não é uma proposta restrita somente à alfabetização de adultos, podendo ser amplamente utilizada em projetos que pretendam consubstanciar-se a partir da realidade, para sua transformação, baseada em um quefazer humanizador.

Segundo Freire, a maneira crítica ${ }^{4}$ de compreender o mundo está atrelada à não negação da "linguagem simples, [...] ingênua, na sua não desvalorização por constituir-se de conceitos criados na cotidianidade, no mundo da experiência sensorial; de outro, na recusa ao que se chama de 'linguagem difícil', impossível, porque desenvolvendo-se em torno de conceitos abstratos" (FREIRE, 1998, p. 33-34).

Freire acreditava que as pessoas ditas comuns, quando interpretam suas próprias experiências, manifestam a complexidade que vão compreendendo através de figuras de linguagem que atrelam seus pensamentos a situações concretas. Por isso, aponta que a forma crítica de compreender e de realizar a leitura do texto e a do contexto não exclui nenhuma das duas formas de linguagem ou de sintaxe (FREIRE, 1998). Os dominantes de ambas sintaxes poderão se sentir desafiados pelas mesmas inquietações e pelos mesmos temas. Logo, torna-se de extrema relevância refletir como "as pessoas comuns, através de suas formas de expressão peculiares e profundamente éticas, são capazes de tornar explícitos os problemas do mundo" (FREIRE, 1986, p. 180).

O conceito de tema gerador é considerado, por grande parte de seus notáveis intérpretes, como um dos mais importantes do legado

4 O conceito de crítica não traz uma sistematização por ele elaborada, mas é possível tomar seu significado como interpretação da própria interpretação, o ato de repensar os contextos, reinventando diversas definições. Não somente tolerando, mas reconhecendo e contrapondo as ambiguidades, de maneira que, a partir dessa competência, seja viável a tentativa de resolver as contradições, questionando os discursos pré-estabelecidos. Para Freire, a capacidade crítica do sujeito encontra-se interdependente da capacidade de nomear as coisas. E por isso tal conceito encontra-se notado neste subtítulo. 
freiriano, haja vista seu potencial de significação das vivências cotidianas. É alertando para o reino da confusão entre os tão discutidos status de verdadeiro e falso, entre conhecimento e falsa consciência, que Freire busca um universo mínimo temático concreto e vivenciado, em que o real se manifeste como síntese de múltiplas relações, determinações e contradições em um mesmo campo tensivo. De acordo com a proposta freiriana, o tema gerador, por dialogar com as experiências dos sujeitos, é generativo e criador, seus valores são significativos e adquiridos pelas experiências cotidianas que (res)significam e atualizam os signos que parturizam pessoas novas. Ele incide na vivificação das inquietações e intencionalidades das pessoas ditas comuns (PASSOS, 2010) e é fruto das codificações que, segundo Freire, "[...] são representações de aspectos da realidade; expressam 'momentos' do contexto concreto" (FREIRE, 1978, p. 111).

Existia, na exposição da experiência freiriana, um movimento de codificação e decodificação da realidade que se valia de materiais que eram projetados ou rusticamente desenhados, para que diversas e simples ilustrações dessem a ideia de representar as pessoas, os próprios participantes. As imagens refletiam as suas atividades, apoiados em suas próprias memórias e experiências de vida, com projetos que correspondessem à sua visão de mundo. O que era extremamente provocativo, fecundo e desestabilizador, pois como alega Tsé-Tung, citado por Freire (2016, p. 144), "pour établir une liaison avec les masses, nous devons nous conformer à leurs désirs. Dans tout travail pour ${ }^{5}$ les masses, nous devons partir de leurs besoins, et non de nos propres désirs, si louables soient-ils"6.

Auxiliado por essas ilustrações, o monitor estimulava a participação de todos no debate, fomentando suas palavras e ideias, a fim de que os participantes começassem a se reconhecer como agentes criadores do mundo e da cultura em que viviam, o que somente era possível, uma

5 Ainda que a tradução da preposição francesa pour seja correntemente para na língua portuguesa, optou-se por lê-la como com em virtude da perspectiva freiriana com a qual aqui se trabalha.

6 Tradução livre: para estabelecer uma conexão com as massas, devemos estar de acordo com seus desejos. Em todo o trabalho com as massas, devemos começar de suas necessidades, e não dos nossos próprios desejos, ainda que louváveis sejam eles. 
vez "que os materiais elaborados [...] se caracterizavam por serem materiais desafiadores e não domesticadores" (FREIRE, 2011, p. 59). Segundo Freire (2016, p. 145) essa prática implicaria

[...] que o acercamento às massas populares se faça, não para levar-lhes uma mensagem "salvadora", em forma de conteúdo a ser depositado, mas, para, em diálogo com elas, conhecer, não só a objetividade em que estão, mas a consciência que tenham desta objetividade; os vários níveis de percepção de si mesmos e do mundo em que e com que estão.

Nesse momento introdutório, o objetivo não se constituía propriamente na elucidação de conceitos atrelados à noção de cultura e trabalho, motivação teórica que não teria significado algum para os participantes. O que interessava era que esses educandos particulares e concretos reconhecessem os impasses da realidade do campo e a si mesmos no transcurso do debate também como criadores de cultura. Nesse sentido que esta categoria ganha relevância no contexto do campo, pela compreensão de que a cultura forma o ser humano e fornece as referências para o modo de educá-lo. Segundo Caldart (2004, p. 21), "são os processos culturais que expressam e garantem a própria ação educativa do trabalho, das relações sociais, das lutas sociais". Com isso, a autora busca recuperar o objetivo central de pensar a cultura como matriz formadora da Educação do Campo, como era em sua concepção mais tradicional. O "que nos ensina que a educação é uma dimensão da cultura, que a cultura é uma dimensão do processo histórico, e que processos pedagógicos são constituídos desde uma cultura e participam de sua reprodução e transformação simultaneamente" (CALDART, 2004, p. 21).

Dentro dessa perspectiva, que considera a questão cultural como motor do processo histórico, os temas geradores, para Freire, fazem parte de um movimento de distanciamento da realidade vivida, com o objetivo de melhor compreendê-la e transformá-la por meio da linguagem que é recriada a partir de tais temas. E, por serem capazes de realizar esse complexo movimento, "que implica em tomar distância do mundo, objetivando-o, que homens e mulheres se fazem seres com o mundo. Sem esta 
objetivação mediante a qual igualmente se objetivam, estariam reduzidos a um puro estar no mundo, sem o conhecimento de si mesmos nem do mundo" (1984, p. 65).

Desse modo, com a característica fundamental de emergir da realidade e dos anseios de quem vive no e do campo, a escolha do tema gerador requer um percurso de muita pesquisa, análise e diálogo entre os envolvidos. De acordo com o que propõe Freire, é nesse momento de busca, de Investigação Temática, que se estabelece o diálogo como prática da liberdade (FREIRE, 2016). "O que se pretende investigar, realmente, não são os homens, como se fossem peças anatômicas, mas o seu pensamento-linguagem referido à realidade, os níveis de sua percepção desta realidade, a sua visão de mundo, em que se encontram envolvidos seus 'temas geradores"' (FREIRE, 2016, p. 148).

\section{Relação entre saberes populares e científicos}

Criador de uma das metáforas mais denunciadoras do contexto educacional, encontra-se em Freire um exercício de libertação ${ }^{7}$ da pedagogia, fazendo dessa uma pedagogia do outro, uma Pedagogia do Oprimido, como apresentado na seção anterior. Nesse sentido, Danilo Streck (2010, p. 331) sustenta que, em se tratando do legado freiriano, "tanto mais se vai à raiz, tanto mais se amplia o círculo de possibilidades". O autor segmenta a necessidade de atualização da perspectiva freiriana em duas tarefas concomitantes:

Precisamos, no sentido em que Freire falava de uma "arqueologia da consciência", de um trabalho de arqueologia pedagógica a fim de reconstruir a memória pedagógica. Outra tarefa consiste em recuperar

7 Segundo José Carlos Libâneo (2005), o caráter libertário da pedagogia freiriana visa levar professores e alunos a atingir um nível de consciência da realidade em que vivem na busca da transformação social, com uma relação calcada na horizontalidade entre os sujeitos, entendendo que o foco da aprendizagem é a resolução da situação problema. 
as pedagogias silenciadas durante séculos de dominação. A "cultura do silêncio" denunciada por Freire nas classes populares também se manifesta nos silenciamentos de práticas educativas transformadoras (STRECK, 2010, p. 331).

Caracterizações semelhantes a essas, expostas por Streck, o tornaram conhecido como andarilho do óbvio, que, assim como Sócrates, deleitava-se com o diálogo especulativo e crítico em cenários considerados bucólicos, todavia não perdia o movimento. Talvez por seu legado mais acessível, no que compete à não-necessidade de tradução, bem como pela sua vasta contribuição, visto que "son innumerables los libros, en todos los idiomas, que sobre él se escribieron. Sin duda, no hay muchos autores contemporáneos capaces de igualar esa producción" (IGLESIAS, 2009, p. 4), a evocação à teoria freiriana se faz de maneira bastante próxima aos impasses sofridos pelo homem do campo no contexto brasileiro.

Freire é uma referência ao falar das relações entre saberes populares e científicos ao tratarmos da Educação do Campo por abordar a relevância de uma compreensão do mundo imediato de cada um, do mundo vivido. Considerando isso, duas influências são proeminentes para que se realize tal análise. A primeira delas advém da proposta marxiana de alienação, pela tendência que as pessoas possuem de considerar o conhecimento organizado como sendo algo em si mesmo, um fim em si mesmo, perdendo de vista suas origens e suas motivações, não o considerando como extensão do processo de reflexão do mundo vivido dos homens. Como ocorre na relação com o trabalho estranhado - trabalho alienado -, ocorre com a produção e reprodução do conhecimento, que sacrifica o movimento intencional dos homens de fazer avançar o processo.

Marx chamou de alienação do trabalho precisamente este fenômeno pelo qual o trabalhador, desenvolvendo a sua atividade criadora em condições que lhe são impostas pela divisão da sociedade em classes, é sacrificado ao produto do trabalho. Para Marx, os regimes baseados na propriedade privada dos meios de produção - sobretudo o capitalismo - tendem a transformar o homem num mero meio para a produção da riqueza particular (KONDER, 1998, p. 38). 
Outra influência bastante característica da teoria freiriana que contribui com a compreensão em questão é a perspectiva de Antonio Gramsci, haja vista sua potencialidade para o desenvolvimento de uma consciência de si-mesmo e para o entendimento dos determinantes da condição de dominado, por meio do conceito de hegemonia. A liderança intelectual hegemônica é também responsável pela sustentação do status quo. "O conceito gramsciano de hegemonia tem dois significados principais: o primeiro é um processo na sociedade civil pelo qual uma parte da classe dominante exerce o controle, através de sua liderança moral e intelectual, sobre outras frações aliadas da classe dominante" (CARNOY, 1990, p. 95). De acordo com a interpretação apresentada por Carnoy (1990, p. 95), a relação entre as classes consistiria nesse segundo significado: "A hegemonia compreende as tentativas bem-sucedidas da classe dominante em usar sua liderança política, moral e intelectual para impor sua visão de mundo como inteiramente abrangente e universal, e para moldar os interesses e as necessidades dos grupos subordinados". A partir das influências de Gramsci (1978), é possível também pensar que a libertação, em Freire, realiza-se problematizada por alguém que defendeu, em algum outro momento, a conscientização inicial partilhada.

Desse modo, retomar as influências de Gramsci auxilia na definição de estratégias políticas à Educação do Campo, mais uma vez, quando reflete relações entre processo e conteúdo e a unidade dialética em que se constituem e, quando engendram, desmistificam a alienação da participação popular na sistematização do conhecimento científico. Entretanto, o enfoque está eminentemente na relação e não na sobreposição de um ou outro movimento.

É indispensável que seja enfocada essa ressalva, uma vez que o caráter opressivo da invasão cultural (FREIRE, 2016) do que é urbano no espaço rural já parece ter sido superado e hoje, com quase duas décadas de avanço da área, se concebe com mais passividade a necessária valorização e problematização daquelas práticas, de uma educação que nasce daquele espaço (FREIRE, 2001). Entretanto, a cautela com o fenômeno quase que contrário é também necessária. 
Pensando no que propõe Moraes, constata-se um fascínio no modo de agir e operar do ato educativo do cotidiano escolar que vêm transformando as experiências discentes e docentes em limites da inteligibilidade. Isso pode ser ratificado quando nas pesquisas "são comuns uma supervalorização da subjetividade do trabalho docente e as célebres 'histórias ou relatos do cotidiano escolar', narrativas subjetivas e/ou descritivas, quase sempre prescritivas, eivadas de 'dever-ser'" (MORAES, 2009, p. 590). Supervalorização essa que, segundo a autora, dificulta a capacidade constitutiva de decifrar os densos desajustes sociais e educacionais como consequência das próprias relações sociais. Além disso, exagera o realismo acerca da conjuntura em que se vive e acerca de "si mesmo, e, nos termos de Freud, identificando-se ao agressor. A crítica deste realismo supervalorizado parece-me ser uma das tarefas educacionais mais decisivas a ser implementada" (ADORNO, 1995, p. 145). Pois a realidade, por ter se tornado tão poderosa, sua adaptação na contemporaneidade é quase categórica e não mediada, fazendo com que somente tenha valor aquilo que nela se materializa. A periculosidade disso, em se tratando da conjuntura do campo, é a facilidade não em identificar-se com as suas condições de existência, mas de conformar-se com elas, com o status quo, e entender como sendo da natureza o que é constituído pelo próprio homem.

A experiência do homem do campo e o conjunto dos saberes populares que desse espaço advém são as raízes do ato educativo, mas desprovidos das reflexões teóricas é meramente visar fins mais imediatos, que consistirá em imprecisões e incongruências peculiares a tal epistemologia da prática, os tolhendo em sua capacidade de capturar as relações funcionais, dialógicas e praxiológicas que poderiam avançar a partir dos fenômenos empíricos (MORAES, 2009). Essa supervalorização proporciona à Educação do Campo fins instantâneos, pois, à rebote, também superestima a cientificidade no sentido de uma técnica aplicada ao ato de ensinar ou à construção de uma metodologia, que geralmente advém do espaço urbanizado - que é análoga à busca momentânea da dominação da natureza pelo homem - porém, o mesmo abdica da liberdade de reflexão mais profunda 
e complexa e, através de um processo mecânico, torna-se escravo de um movimento que deveria ser fruto de seu próprio trabalho reflexivo.

Quanto maior a perfeição com que descompromissadas epistemologias da prática duplicam os objetos empíricos, mais fácil se torna hoje obter a ilusão de uma atividade engajada e democrática, sob a rasa compreensão de caros e relevantes conceitos como intercultura, diversidade, multiculturalismo e diferença. Conceitos esses que se desgastam, perdem sua rigorosidade e seu potencial de resistência, homogenizando perspectivas quase antagônicas. Quanto a isso, "no se trata de establecer un Index verborum prohibitorum de sustantivos nobles, corrientes en el mercado, sino de investigar su función lingüística en la jerga" (ADORNO, 1987, p. 11). O problema não está na existência ou no uso daqueles e de outros termos tendencialmente adotados pelo discurso pedagógico da Educação do Campo. O perigo está em sua leitura apressada e utilização precipitada e pouco refletida, que faz com que os saberes populares do homem do campo sejam referenciados, mas que não avancem no sentido de dialogar com - e se inserir nos - saberes científicos e, de forma dissimulada e silenciosa, o utilitarismo e a coisificação do homem se reforçam.

\section{Considerações finais}

Como ponto pacífico entre os grandes teóricos que têm se dedicado à temática, a evolução do conceito de educação rural para educação do campo evidencia a meta de superação de um modelo de dominação através da educação para uma forma educativa que tenha como parâmetro aqueles que vivem no e do campo. Nesse sentido, "[...] como toda chegada é um movimento, estamos de novo em um ponto de partida [...], nenhuma conquista é garantida sem organização permanente" (FERNANDES, 2002, p. 62). Alguns passos foram dados, mas ainda há muito a avançar.

Assim, que esse texto possa constituir-se como mais um passo, pois em Freire é encontrada a insistência na articulação entre teoria e prática pedagógica, a defesa dos direitos humanos, das utopias e da esperança, 
contribuições à educação do campo, inseridas em um projeto de sociedade diversa da atual, mais justa e solidária. Que a reflexão sobre as contribuições de inspiração freiriana às práticas pedagógicas do campo contribuam com a construção de uma sociedade radicalmente humana, em que floresça a certeza da possibilidade de mudança. Pois, marca este escrito a convicção na importância da discussão sobre a escola pública, na perspectiva de que somente através dessa, os esfarrapados do mundo terão acesso ao conhecimento sistematizado, necessário à defesa de seus interesses.

Para tanto, é necessário que a educação não seja meio de fuga do campo, mas de obtenção de melhoria das condições de vida; reivindicação de um projeto de educação atrelado ao modelo de agricultura que não mate a dignidade do ser humano; defesa e exigência de escola enraizada na Educação Popular e na Pedagogia do Oprimido e, embora a escolarização seja uma preocupação, a meta é uma educação que compreenda todos os processos sociais da formação de pessoas como sujeitos de seu próprio destino, em que a emancipação encontra-se em oposição à domesticação.

\section{Referências}

ADORNO, T. W. Educação e emancipação. Rio de Janeiro: Paz e Terra, 1995.

ADORNO, T. W. La ideología como lenguaje. Trad. Justo Pérez Corral. Madrid: Taurus, 1987.

ANTONIO, C. A.; LUCINI, M. Ensinar e aprender na educação do campo: processos históricos e pedagógicos em relação. Cadernos Cedes, Campinas, v. 27, n. 72, p. 177-195, mai./ago. 2007.

ARENDT, H. A Condição Humana. Rio de Janeiro: Forense Universitária, 1997.

ARROYO, M. G. Ofício de Mestre: Imagens e auto-imagens. Petrópolis: Vozes, 2000. 
BRASIL. Decreto No 7.352, de 4 de novembro de 2010. Dispõe sobre a política de educação do campo e o Programa Nacional de Educação na Reforma Agrária PRONERA. Disponível em: <http://www.planalto.gov.br/ccivil_03/_ato20072010/2010/decreto/d7352.htm>. Acesso em: 15 jun. 2017.

CALDART, R. S. A escola do campo em movimento. Currículo sem Fronteiras, v. 3, n. 1, p. 60-81, jan./jun. 2003.

CALDART, R. S. Elementos para construção do Projeto Político e Pedagógico da Educação do Campo. In: MOLINA, M. C.; AZEVEDO DE JESUS; S. M. S. (Orgs.). Contribuições para a Construção de um Projeto de Educação do Campo. Coleção Por Uma Educação do Campo, n. 5. Brasília: Articulação Nacional Por Uma Educação do Campo, 2004. p. 10-31.

CARNOY, M. Estado e teoria política. 3. ed. Campinas: Papirus, 1990.

FERNANDES, B. M. Diretrizes de uma caminhada. In: KOLLING, E. J., CERIOLI, P. R., CALDART, R. S. (Orgs.). Educação do campo: identidade e políticas públicas. Brasília: Articulação Nacional Por Uma Educação do Campo, 2002. p. 61-75. (Coleção Por Uma Educação do Campo, n. 4).

FREIRE, P. A importância do ato de ler: em três artigos que se completam. 51. ed. São Paulo: Cortez Editora, 2011.

FREIRE, P. Cartas a Guiné-Bissau: registros de uma experiência em processo. Rio de Janeiro: Paz e Terra, 1978.

FREIRE, P. Educação e Mudança. 24. ed. Rio de Janeiro: Paz e Terra, 2001.

FREIRE, P. Medo e Ousadia. O Cotidiano do Professor. Rio de Janeiro: Paz e Terra, 1986.

FREIRE, P. Pedagogia da Indignação: cartas pedagógicas e outros escritos. São Paulo: Editora UNESP, 2000.

FREIRE, P. Pedagogia do Oprimido. 60. ed. Rio de Janeiro: Paz e Terra, 2016.

FREIRE, P. Professora sim, Tia não: Cartas a quem ousa ensinar. São Paulo: Olho d'água, 1998. 
GIL, A. C. Como elaborar projetos de pesquisa. 4. ed. São Paulo: Editora Atlas, 2002.

GOHN, M. da G. Educação Popular na América Latina no novo milênio: impactos do novo paradigma. ETD- Educação Temática Digital, Campinas, v. 4, n. 1, p. 5377, dez. 2002.

GRAMSCI, A. Obras Escolhidas. São Paulo: Martins Fontes, 1978.

IGLESIAS, R. Trabajar com la gente - Pefacio. In: FREIRE, P. El grito manso. 2. ed. Buenos Aires: Siglo Veintiuno Editores, 2009. p. 03-06.

KONDER, L. O futuro da filosofia da práxis. 2. ed. Rio de Janeiro: Paz e Terra, 1992. KONDER, L. Marx: vida e obra. São Paulo: Perez, 1998.

LIBÂNEO, J. C. As teorias pedagógicas modernas revisitadas pelo debate contemporâneo na educação. In: LIBÂNEO, J. C.; SANTOS, A. (Orgs.). Educação na era do conhecimento em rede e transdisciplinaridade. Campinas: Alínea, 2005. p. 19-63.

LUNA, S. V. Planejamento de pesquisa: uma introdução. São Paulo: EDUC, 1999. MORAES, M. C. M. de. "A teoria tem consequências": indagações sobre o conhecimento no campo da educação. Educação \& Sociedade, Campinas, v. 30, n. 107, p. 585-607, mai./ago. 2009.

NOSELLA, P. Origens da pedagogia da alternância no Brasil. Vitória/Espírito Santo: EDUFES, 2012.

PASSOS, L. A. Tema Gerador. In: STRECK, D. R.; REDIN, E.; ZITKOSKI, J. J. (Orgs.). Dicionário Paulo Freire. 2. ed. Belo Horizonte: Autêntica Editora, 2010. p. 388-390.

PELIZZARI, C.; PIETROSKI, C. J.; PALUDO, C. Escolas do campo: encontros e desencontros do processo avaliativo. In: MACHADO, C. L. B.; CAMPOS, C. S. S.; PALUDO, C. (Orgs.). Teoria e prática da educação do campo: análises de experiências. Brasília: MDA, 2008. p. 74-83. 
PINGAS, M. R. Educação Matemática no cotidiano da Escola Itinerante Olga Benário do Assentamento Celso Furtado e a relação com a cultura camponesa Sem Terra. 2006. Trabalho de Conclusão de Curso (Graduação em Pedagogia) - ITERRA/ Universidade Estadual do Rio Grande do Sul (UERGS), Veranópolis, 2006.

PINTO, P. E. A cultura camponesa no processo de ensino-aprendizagem da Escola Itinerante Herdeiros de Paulo Freire. 2006. Trabalho de Conclusão de Curso (Graduação em Pedagogia) - ITERRA/Universidade Estadual do Rio Grande do Sul (UERGS), Veranópolis.

SAUL, A. M.; SILVA, A. G. A matriz de pensamento de Paulo Freire: um crivo de denúncia-anúncio de concepções e práticas curriculares. Revista e-Curriculum, São Paulo, v. 12, n. 03 p. 2064-2080, out./dez. 2014.

SAVIANI, D. Educação: do senso comum à consciência filosófica. 12. ed. Campinas: Autores Associados, 1996.

SEVERINO, A. J. Metodologia do Trabalho Científico. São Paulo: Cortez Editora, 2002. STRECK, D. Paulo Freire e a consolidação do pensamento pedagógico na America Latina. In: STRECK, D. (Org.). Fontes da pedagogia latino-americana: uma antologia. Belo Horizonte: Autêntica Editora, 2010. p. 329-345.

Recebido: 03/05/2018

Received: 05/03/2018

Recibido: 03/05/2018

Aprovado: 24/07/2018 Approved: 07/24/2018 Aprobado: 24/07/2018 